
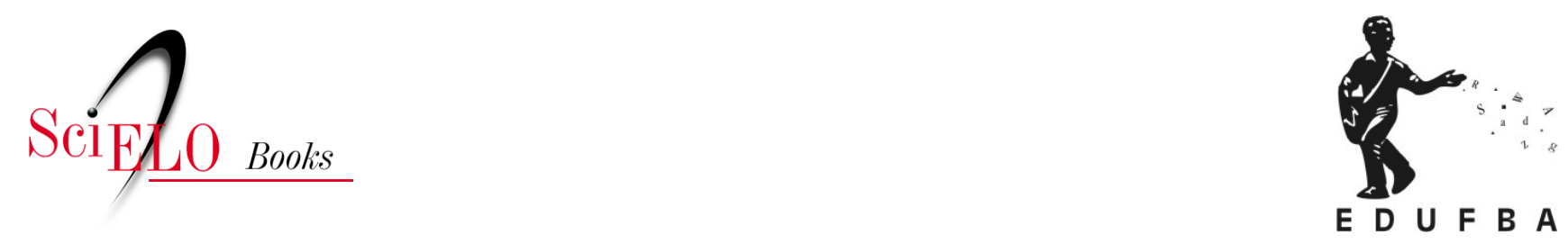

\title{
“Gente é encomenda?" ou um preâmbulo que se faz necessário
}

\author{
Danila Gentil Rodriguez Cal
}

\section{SciELO Books / SciELO Livros / SciELO Libros}

CAL, D.G.R. “Gente é encomenda?” ou um preâmbulo que se faz necessário. In: Comunicação e trabalho infantil doméstico: política, poder, resistências [online]. Salvador: EDUFBA, 2016, pp. 1519. ISBN: 978-85-232-1870-6. https://doi.org/10.7476/9788523218706.0002.

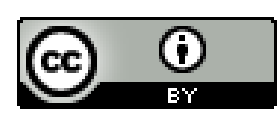

All the contents of this work, except where otherwise noted, is licensed under a Creative Commons Attribution $\underline{4.0 \text { International license. }}$

Todo o conteúdo deste trabalho, exceto quando houver ressalva, é publicado sob a licença Creative Commons Atribição 4.0. 


\section{“Gente é encomenda?” ou um preâmbulo que se faz necessário}

Sala escura. Ao fundo, uma melodia suave. Três pesquisadoras da Universidade Federal do Pará à frente de um auditório cheio, a contar um trecho de uma prosa “Belém do Pará”, escrita pelo marajoara Dalcídio Jurandir (1960, p. 33-34):

- O nome da canoa é "Deus te guarde", do Moju. Venho ver uma encomenda. [...]

O tripulante [...], num átimo trouxe a encomenda da senhora: uma menina de nove anos, amarela, descalça, a cabeça rapada, o dedo na boca, metida num camisão de alfacinha. A senhora recuou um pouco o leque dos lábios, examinando-a:

- Mas isto?

E olhava para a menina e para o canoeiro, o leque impaciente:

- Mas eu lhe disse que arranjasse uma maiorzinha pra serviços pesados. Isto aí... 
O canoeiro respondia baixo, se enchendo de respeitosas explicações, fazendo valer a mercadoria. A menina, de vez em vez, fitava a senhora com estupor e abandono. [...]

- Bem. Vamos ver. O compadre me leva ela. Não posso levar comigo como está. E como é o teu nome? O teu nome, sim. É muda? É surda-muda? Não te batizaram? És pagoa? É parece malcriada, parece que precisa de uma correção. Fala, tapuru, bicho do mato. Ai, esta consumição...

Aquele foi meu primeiro contato com o Trabalho Infantil Doméstico (TID). Na época (2001), era estagiária de Comunicação no Fundo das Nações Unidas para a Infância (Unicef) e havia sido convidada para participar do lançamento de uma pesquisa sobre trabalho infantil em Belém. Representantes do Unicef e de outros organismos internacionais, atores sociais e agentes públicos locais aguardavam pela apresentação dos resultados obtidos. O estudo, realizado por uma psicóloga, uma socióloga e uma assistente social, não trazia informações estatísticas. Ele mostrava e discutia desenhos feitos por 16 adolescentes trabalhadoras domésticas. Nunca tinha visto o lançamento de uma pesquisa daquele jeito.

Em seguida à apresentação da prosa de Dalcídio Jurandir, as autoras continuaram a encenação, mas, desta vez, lendo os comentários das meninas entrevistadas, construídos a partir da descrição dos desenhos. Emocionei-me ao ouvir aquelas histórias. Meninas que estudavam à noite em escolas de bairros centrais de Belém e que vieram de outros municípios do Pará ou do Maranhão para morar e trabalhar nas casas de outras famílias. Não que eu não conhecesse aquela realidade, mas nunca a tinha visto daquele jeito.

Desde pequena, acostumei-me a ver meninas morenas ou negras de vestido e chinelo cuidando de outras crianças. No início da adolescência, nas casas das minhas avós, acompanhei meninas com 14 ou 15 anos que trabalhavam enquanto eu brincava, via televisão ou curtia a família. Elas tinham seus próprios quartos, sempre próximos à cozinha. Só hoje, ao escrever este texto, recordo-me desse fato. Elas dormiam ali mesmo, bem próximas à cozinha. Ainda que tivessem quarto próprio, ele era ao lado do seu local de maior trabalho, onde lavavam louça, limpavam e ajudavam minhas avós a cozinhar. O restante dos quartos, os dos filhos, em ambas as casas, ficam próximos à sala. Lembro que uma das meninas corria para lavar a louça do almoço e seguir para a escola. A outra, sei que estudava, mas não recordo se era à noite ou durante o dia. 
Até aquela apresentação, eu conhecia meninas que cuidavam da casa, de crianças e que viviam com famílias que não eram suas. O que eu ainda não tinha percebido é de onde elas tinham vindo, o que esperavam da vida e o porquê de eu achar aquela situação algo esperado para meninas pobres. Até então, não conhecia o “Trabalho Infantil Doméstico” como conceito, construído por organizações sociais que lutavam pelos direitos da infância. Posso dizer que aquele momento me afetou como um acontecimento, que modificou o olhar que lancei sobre o passado e sobre minhas perspectivas futuras.

Engajei-me no enfrentamento ao TID - a preferência institucional era não usar o termo "luta” para não remeter à violência e ao combate agonístico dessa prática - e participei, como estagiária do Unicef, da criação do Programa de Enfrentamento ao Trabalho Infantil Doméstico no Pará, chamado de Petid. Quem o desenvolvia era o Centro de Defesa da Criança e do Adolescente do Pará (Cedeca-Emaús) em parceria com outras organizações internacionais e locais. Lembro de ter acompanhado uma reunião com a agência de publicidade que faria a primeira campanha contra o TID. Discutíamos sobre os sentidos de dignidade e se deveríamos usar essa palavra nos produtos. Dentre tantas lembranças, hoje percebo com mais clareza a importância de ter guardado, após tanto tempo, algo daquela conversa.

Dois anos depois, quando chegou o momento de elaborar meu trabalho de conclusão de curso de graduação, só pensei em abordar o tema do trabalho infantil doméstico. Naquela época, buscava perceber o sucesso do processo de mobilização social contra essa prática. Estudei várias referências na área de Comunicação e Mobilização Social e escolhi como objeto o caso do enfrentamento ao TID em Soure, na Ilha do Marajó, por dois motivos: primeiro, porque me parecia uma ação bem sucedida e, segundo, porque, por ser circunscrita a um município pequeno, parecia-me mais viável e analisável.

Um dos examinadores da banca de defesa era um pesquisador alemão radicado em Belém. A sua participação foi motivo da várias noites de preocupação, afinal ele havia lido Habermas - autor que, na época, já era decisivo para meu trabalho - no original, e eu estava apenas tateando a teoria da ação comunicativa com os poucos livros dele disponíveis em Belém no início dos anos 2000. As críticas pertinentes e generosas que ele fez ao trabalho me fizeram refletir sobre minhas conclusões naquele momento. Uma pergunta especificamente me interpela até hoje: “E os sujeitos?”, indagou-me ele sobre como os próprios afe- 
tados construíam sentidos acerca do TID. Passaram-se mais de dez anos e ainda persigo essa resposta.

Depois da graduação, o assunto do TID continuou a me instigar, e elaborei meu projeto de mestrado em Comunicação, cujo objeto de pesquisa era a experiência do Petid em Belém. Aprofundei minha investigação na cobertura dos jornais impressos e nas campanhas construídas de enfrentamento a esse problema. Vivi, então, o dilema de lançar um olhar crítico àquele processo ao qual havia acompanhado e à ação de instituições nas quais tinha trabalhado e sido parceira. Confesso que não foi uma passagem tranquila. Eis que me dava conta de que o discurso do TID que construímos com bastante prudência e cuidado, apesar de ganhar visibilidade e espaço nos media, não repercutia no dia a dia das casas de família onde meninas trabalhavam. Ao ouvir mulheres patroas, concluí que era a forma mesma do discurso que as fazia entender que aquilo do qual o Petid ou os jornais falavam era a exploração do TID, e não o tipo de atividade que ocorria nos lares das entrevistadas.

Depois da dissertação, já trabalhando como professora universitária, tive oportunidade de ministrar cursos e seminários sobre direitos da criança, trabalho infantil e comunicação. A vida pessoal também seguia. Casei, tive um filho e, no momento de voltar ao trabalho, achei que precisaria de uma babá. Recebi algumas ofertas de pessoas que diziam ter meninas de confiança que poderiam me ajudar. Vi amigas recorrerem a adolescentes para cuidarem de seus bebês. A cada visita ao pediatra ou ida ao supermercado, lá estavam as meninas domésticas morenas ou negras cuidando de crianças.

Mesmo tendo contratado, em diferentes momentos, mulheres adultas para cuidarem do meu filho, o TID estava ali, nas histórias que elas me diziam, na forma como percebiam ser o lugar delas na minha casa e na minha vida.

Fui tocada profundamente por aquelas vivências.

Um professor do doutorado me disse certa vez que ele se via como um entreposto. Afirmou que sua pesquisa e seu olhar sobre a pesquisa eram atravessados pelos filmes que viu, pelos livros que leu, pelas interações com os amigos, que lhe sugeriram caminhos, pelos professores, orientadores e alunos com os quais havia convivido. Os resultados de seus estudos eram credores de todas essas experiências e pessoas, ao mesmo tempo em que eram transformados e configurados como um novo, sempre sujeito a revisões e experiências. Esse é o espírito da pesquisa que apresento. Trata-se de um conjunto de experiências e 
afetações que vivi em relação ao TID, atravessado pelas teorias e metodologias, pelos professores, pelo processo de orientação e pelas meninas e mulheres que entrevistei; transformado pelo meu olhar. Assim, o que busco é lançar luz sobre o espaço simbólico que sustenta e que pode também desafiar o TID. O produto disso, este livro, coloca-se como entreposto e um espaço aberto a futuras pesquisas e vivências. 